Abstract P-041 Table 2 Patient characteristic and outcome data of the severe chronic headache group

\begin{tabular}{|c|c|c|c|c|c|c|c|c|}
\hline \multirow[b]{2}{*}{ Case } & \multirow[b]{2}{*}{ Age } & \multirow[b]{2}{*}{ Sex } & \multirow{2}{*}{$\begin{array}{c}\text { Pre-embolization } \\
\text { medications for } \\
\text { headaches }\end{array}$} & \multirow{2}{*}{$\begin{array}{c}\text { Bilateral } \\
\text { embolization }\end{array}$} & \multirow{2}{*}{$\begin{array}{c}\text { Headaches after } \\
\text { embolization }\end{array}$} & \multicolumn{2}{|c|}{ HIT-6 score } & \multirow{2}{*}{$\begin{array}{c}\text { Phone } \\
\text { follow-up } \\
d^{*}\end{array}$} \\
\hline & & & & & & $\begin{array}{c}\text { Pre- } \\
\text { embolization }\end{array}$ & $\begin{array}{c}\text { Post- } \\
\text { embolization }\end{array}$ & \\
\hline 1 & 59 & Female & Acetaminophen & No & Resolved & 61 & 36 & 568 \\
\hline 2 & 45 & Female & Ibuprofen & No & $\begin{array}{l}\text { Worse, requires } \\
\text { more medication }\end{array}$ & 60 & 63 & 850 \\
\hline 3 & 77 & Male & None & Yes & Resolved & 57 & 36 & 621 \\
\hline 4 & 65 & Female & Triptan & No & $\begin{array}{l}\text { Improved, } \\
\text { requires less } \\
\text { medication }\end{array}$ & 67 & 44 & 527 \\
\hline 5 & 74 & Male & Ibuprofen & Yes & Resolved & 54 & 36 & 429 \\
\hline 6 & 74 & Male & None & Yes & Resolved & 60 & 36 & 405 \\
\hline 7 & 47 & Male & Aspirin & Yes & Resolved & 72 & 36 & 338 \\
\hline 8 & 72 & Female & Ibuprofen & Yes & Resolved & 70 & 36 & 304 \\
\hline 9 & 62 & Female & None & Yes & Resolved & 74 & 36 & 360 \\
\hline
\end{tabular}

Abstract P-041 Table 1 Demographics and characteristics of CSDH patients with a GCS score of 15 at discharge

\begin{tabular}{lc}
\hline Characteristics & $\begin{array}{c}\text { No. (\%) } \\
(\mathbf{n}=46)\end{array}$ \\
\hline Age, mean \pm SD, y & $68 \pm 11$ \\
Sex & \\
Female & $10(22)$ \\
Male & $36(78)$ \\
Chronic headache & $9(20)$ \\
Any headache before embolization & $25(54)$ \\
Any headache after embolization & $7(15)$ \\
New headache after embolization & $1(5)$ \\
(n=21 w/o previous headache) & \\
Complications & $0(0)$ \\
\hline
\end{tabular}

Abbreviations: cSDH, chronic subdural hematoma; GCS, Glasgow Coma Scale Data are reported as number (pereent) unless otherwise indicated.

(20\%) reported chronic headaches before embolization. With a mean follow-up of 489 (173) days, 8 of the 9 patients reported improvement of chronic headaches, with 7 having complete resolution. For these 9 patients, the mean HIT-6 score before was significantly higher than after embolization (64 [7.1] vs 40 [9.1], p<0.001).

Conclusion In patients with chronic headache undergoing MMA embolization for a cSDH, the majority reported improvement of headaches after the procedure. Future prospective studies are warranted to assess the utility of MMA embolization for chronic headaches.

Disclosures J. Catapano: None. K. Karahalios: None. V. Srinivasan: None. J. Baranoski: None. C. Rutledge: None. T. Cole: None. A. Ducruet: None. F. Albuquerque: None. A. Jadhav: None.

\section{P-042 INITIAL EXPERIENCE WITH TENECTEPLASE AS THE INTRAVENOUS THROMBOLYTIC OF CHOICE BEFORE MECHANICAL THROMBECTOMY FOR LARGE VESSEL OCCLUSION ACUTE ISCHEMIC STROKE}

\footnotetext{
${ }^{1,2} \mathrm{U}_{\text {Ugur, }}{ }^{1,2} \mathrm{~S}$ Platko, ${ }^{3} \mathrm{D}$ Peters, ${ }^{2} \mathrm{~F}$ Bensabeur, ${ }^{1,2} \mathrm{~J}$ Terry, ${ }^{1,2} \mathrm{~B}$ Ludwig, ${ }^{1,2} \mathrm{E}$ Cheng-Ching ${ }^{*}$. ${ }^{1}$ Neurology, Miami Valley Hospital, Dayton, $\mathrm{OH}_{;}{ }^{2}$ Neurology, Wright State University, Dayton, $\mathrm{OH} ;{ }^{3}$ Pharmacy, Miami Valley Hospital, Dayton, $\mathrm{OH}$
}

10.1136/neurintsurg-2021-SNIS.78
Introduction In mechanical thrombectomy (MT) candidates, tenecteplase (TNK) has shown improved reperfusion and outcomes. Therefore, in October of 2020, we transitioned to TNK as the primary thrombolytic for patients presenting with large vessel occlusion acute ischemic stroke (LVOAIS). We describe our initial experience.

Methods In this retrospective study, demographic, clinical, and imaging information from patients with LVOAIS treated with TNK was collected. Data was compared to a group treated with MT and intravenous alteplase (tPA).

Results Between October 2020 and March 2021, 14 patients received TNK for LVOAIS. Mean age was 71.4 years. Of the TNK patients, 5 presented directly to the comprehensive stroke center (CSC), and 9 were transferred from telestroke spoke sites within the system. Median initial NIHSS was 16. All patients had either an LVO on CTA, or high suspicion based on high NIHSS. Occlusion locations included the MCA in 9 (7 M1, 2 M3-4 with CTA obtained after TNK), ACA 1, PCA 1, ICA terminus 1 , and 2 with occlusion involving the internal carotid artery (ICA) from the origin to the terminus. Three patients (21\%) improved clinically prior to MT and did not undergo this intervention, and $2(14 \%)$ had a cerebral angiogram demonstrating recanalization without MT. One patient with occlusion from ICA origin to terminus underwent revascularization of the ICA origin with distal spontaneous recanalization. Eight patients underwent MT with 7 achieving TICI 2b-3. Symptomatic hemorrhage $(\mathrm{SICH})$ rate was $7.1 \%$. Length of stay (LOS) was 4.4 days, with median discharge NIHSS of 4. In comparison, of patients who received tPA prior to MT none recanalized prior to MT, median discharge NIHSS was 6 , rate of SICH was $5.1 \%$ and LOS was 8.54 days.

Discussion In our initial experience in a small cohort, the recanalization rate was high with TNK in patients with LVOAIS, with $36 \%$ of TNK patients not requiring MT either due to clinical improvement or recanalization pre-MT. In comparison, no patient who received tPA recanalized prior to MT. Discharge NIHSS and LOS was lower in patients receiving TNK.In light of evidence supporting TNK in LVOAIS, we were able to transition easily to adopt the use of TNK within our system. The practicality of a single bolus without subsequent infusion of TNK will likely improve the treatment process of LVOAIS patients by facilitating transfer from ER to the angio-suite as well as from spokes to hub. With 
TNK cost being lower than tPA, and in addition to potential reduced ER stay and waiting time prior to transport, improved recanalization, reduction in MT need, shorter hospitalizations, and improved outcomes, significant cost reduction may be achieved. Further study of these factors is needed.

Conclusion Intravenous TNK in patients with LVOAIS is feasible, safe and effective. In our cohort from 'real world' patients, TNK was associated with lower need for MT, high recanalization rates and shorter hospitalization.

Disclosures U. Ugur: None. S. Platko: None. D. Peters: None. F. Bensabeur: None. J. Terry: None. B. Ludwig: None. E. Cheng-Ching: None.

\section{P-043 ELEVATED D-DIMER LEVELS PREDICTS MORTALITY IN COVID-19 WITH STROKE: ANALYSIS OF MULTI-CENTER ELECTRONIC HEALTH RECORD DATA}

Y Kim*, S Khose, R Abdelkhaleq, S Salazar-Marioni, S Sheth. Department of Neurology, UTHealth MGovern Medical School, Houston, TX

10.1136/neurintsurg-2021-SNIS.79

Introduction Coronavirus disease (COVID-19) has been associated with coagulopathy, and D-dimer levels have been implicated as predictors of disease severity. In this study, we examined whether D-dimer remains useful to predict mortality in COVID-19 patients presenting with acute ischemic stroke (AIS).

Methods We conducted a retrospective cohort study using the Optum $^{\circledR}$ de-identified COVID-19 Electronic Health Record (EHR) dataset. Patients were included if they were 18 and older, were hospitalized within 7 days of confirmed COVID19 from March 1, 2020 - November 30, 2020, and were tested for D-dimer during their hospitalization. ICD-9 and 10 diagnostic codes were used to identify AIS and comorbidities. D-dimer level was evaluated using receiver-operator curve analysis for the optimal threshold to predict in-hospital mortality and Kaplan-Meier survival curves were constructed. Risks of in-hospital mortality were compared between patients with D-dimer levels below and above the cutoff and risk ratios (RRs) were estimated adjusting for baseline characteristics and clinical variables.

Results Among 15,250 patients hospitalized with COVID-19 positivity, 285 presented with AIS at admission (2\%). Patients with AIS were older (median age 70 [60-79] vs 64 [52-75]) and had higher prevalence of congestive heart failure, hypertension, diabetes, vascular disease and atrial fibrillation. Ddimer levels at admission were greater for patients presenting with AIS (median [IQR], 1.42 [0.76-3.96] $\mu \mathrm{g} / \mathrm{ml}$ feu) compared to those without AIS $(0.94[0.55-1.81] \mu \mathrm{g} / \mathrm{ml} \mathrm{feu})$ and peak levels were also greater for patients with AIS (3.86 [1.23-15.58] vs $1.42[0.76-3.96] \mu \mathrm{g} / \mathrm{ml}$ feu). Peak D-dimer level was a good predictor of in-hospital mortality among all patients (c-statistic 0.774 [95\% CI 0.764-0.784]) and among patients with AIS (c-statistic 0.751 [95\% CI 0.691-0.810]). The optimum cutoff threshold was identified as $2.07 \mu \mathrm{g} / \mathrm{ml}$ feu with $72 \%$ sensitivity and $70 \%$ specificity, and elevated peak D-dimer level above this threshold was associated with increased mortality (adjusted RR 3.00 [95\% CI 2.75-3.28]) among all patients. Among AIS patients, the optimum cutoff threshold was identified at $5.15 \mu \mathrm{g} / \mathrm{ml}$ feu with $73 \%$ sensitivity and 69\% specificity. Elevated peak D-dimer level above
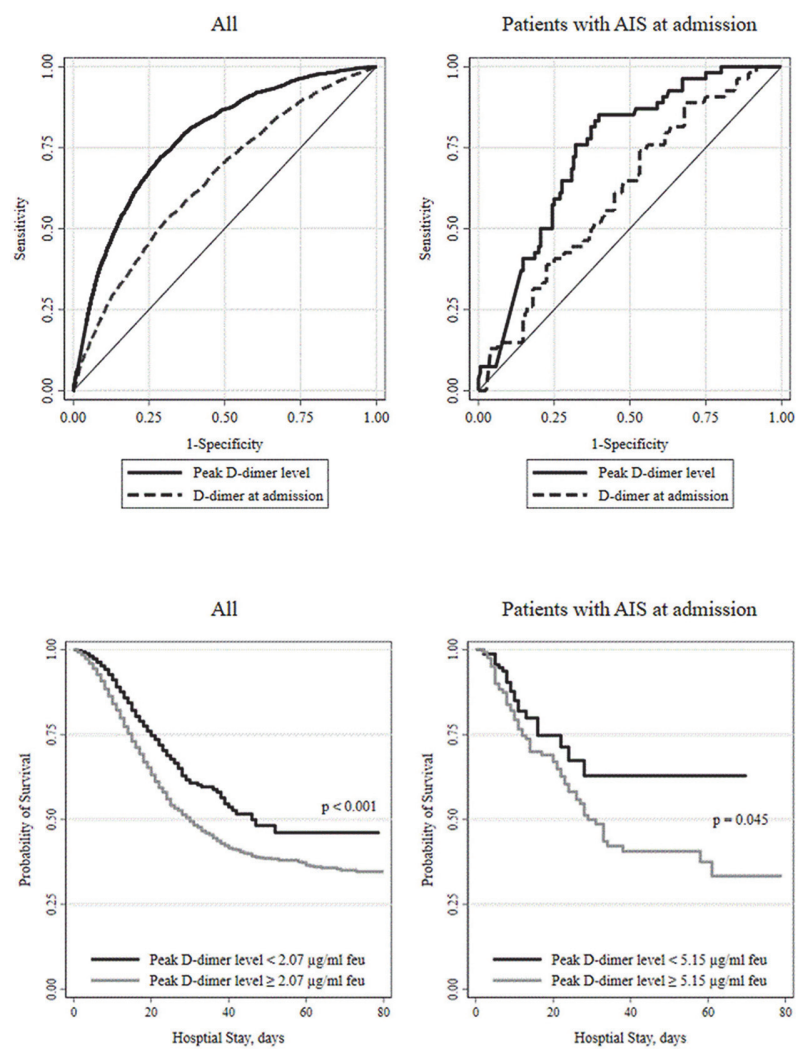

Abstract P-043 Figure 1 A Receiver operator characteristic curves for D-dinier to predict deaths in COVID-19; B. Kaplan-Meier survival estimates

this cut-off was associated with almost 3 times increased mortality (adjusted RR 2.89 [95\% CI 1.87-4.47]).

Conclusions Peak D-dimer levels above $5.15 \mu \mathrm{g} / \mathrm{ml}$ feu are associated with increased mortality in COVID-19 patients with AIS.

Disclosures Y. Kim: None. S. Khose: None. R. Abdelkhaleq: None. S. Salazar-Marioni: None. S. Sheth: None.

\section{P-044 PRIMARY RESULTS OF THE VESALIO NEVA VS FOR THE TREATMENT OF SYMPTOMATIC CEREBRAL VASOSPASM FOLLOWING ANEURYSM SUBARACHNOID HEMORRHAGE (VITAL) STUDY}

${ }^{1} \mathrm{R}$ Gupta*${ }^{2}{ }^{2} \mathrm{~K}$ Woodward, ${ }^{3} \mathrm{D}$ Fiorella, ${ }^{4} \mathrm{H}$ Woo, ${ }^{5} \mathrm{D}$ Liebeskind, ${ }^{6} \mathrm{D}$ Frei, ${ }^{7} \mathrm{~A}$ Siddiqui, ${ }^{8} \mathrm{R}$ Deleacy, ${ }^{9} \mathrm{R}$ Hanel, ${ }^{10} \mathrm{~A}$ Maud. 'WMG Neurosurgery, Wellstar Health System, Marietta, GA; ${ }^{2}$ Department of Radiology, Fort Sanders Regional Medical Center, Knoxville, TN; ${ }^{3}$ Cerebrovascular Center, Stony Brook University, Setauket- East Setauket, NY; ${ }^{4}$ Department of Neurosurgery, North Shore University Hospital, Manhasset, NY; ${ }^{5}$ Department of Neurology, University of California Los Angeles, Los Angeles, CA; ${ }^{6}$ RIA Neurovascular, Radiology Imaging Associates, Englewood, CA; 'Department of Neurosurgery, SUNY Buffalo, Buffalo, NY; ${ }^{8}$ WMG Neurosurgery, Mount Sinai Health System, New York, NY; ${ }^{9}$ Department of Neurosurgery, Baptist Neurological Institute, Jacksonville, FL; ${ }^{10}$ Department of Neurology, Texas Tech Health Sciences Center, El Paso, TX

\subsection{6/neurintsurg-2021-SNIS.80}

Introduction Cerebral vasospasm after aneurysmal subarachnoid hemorrhage is linked to delayed cerebral ischemic and worse neurological outcomes. Pharmacological treatment with intraarterial vasodilators allows for transient improvement in cerebral perfusion. Balloon angioplasty may provide durable luminal gain, but risks vessel rupture and thromboembolic events. The Neva VS is a novel cerebral dilation device based on 